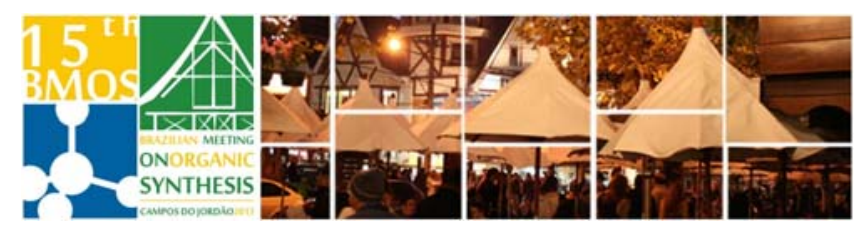

\title{
Synthesis of ligands for nuclear receptors of thyroid hormones
}

\author{
Guilherme V. de Castro ${ }^{1 *}$; Vitor Lacerda Sanches²; Paulo M. Donate²; Igor \\ Polikarpov; ; Mirela I. de Sairre ${ }^{1}$ \\ 1 UFABC, Centro de Ciências Naturais e Humanas, Laboratório de Biologia Química \\ 2 USP, Faculdade de Filosofia, Ciências e Letras de Ribeirão Preto, Departamento de Química \\ ${ }^{3}$ USP, Instituto de Física de São Carlos, Departamento de Física e Informática \\ *guilhermevdecastro@gmail.com
}

Keywords: Thyroid Hormones, Nuclear Receptors, Ligands.

\section{INTRODUCTION}

The thyroid hormones (TH) (Figure 1), thyroxine $\left(T_{4}\right)$ and triiodo L-thyronine $\left(T_{3}\right)$, influence growth, development and homeostasis, with important effects on general metabolism, lipid levels, heart rate and mood. Pharmacologic thyroid hormone treatment could be used to combat obesity, lower cholesterol and triglyceride levels but fails in practice because of associated symptoms of hyperthyroidism, in particular, elevated heart rate and arrhythmia. ${ }^{1,2}$
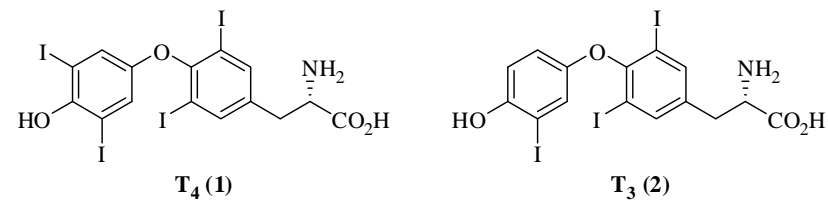

Figure 1. Thyroid hormones, $\mathbf{T}_{4}(\mathbf{1})$ and $\mathbf{T}_{3}(2)$.

The TH effects are mediated by the thyroid hormone receptors (TRs), transcription factors that bind to DNA via specific sequences, in promoters of target genes. The TRs are present in cells in two isoforms, TRa and TRß, and several lines of evidence showed that the development of ligands that bind to TR $\beta$ could lead to safer therapies for the disorders cited above.

In this work, we report a synthetic route, shown in scheme 1 , which allows the obtaining of two new ligands to TRs planned by structure-activity relationship (SAR) studies.

\section{RESULTS AND DISCUSSION}

All the compounds prepared were submitted to spectroscopic analysis (Infrared spectroscopy, nuclear magnetic resonance of ${ }^{1} \mathrm{H}$ and ${ }^{13} \mathrm{C}$, and mass spectrometry), confirming the structure of the intermediates and the products.

According to scheme 1 , the intermediate compounds $\mathbf{4}$ and $\mathbf{6}$ were prepared and then were coupled to give the biaryl alcohol 7 (43\% yield), which was submitted to the hydrogenolysis reaction, followed by instantaneous deprotection of the silicon group with tetrabutylammonium fluoride (TBAF), providing the ligand $\mathbf{9}$.

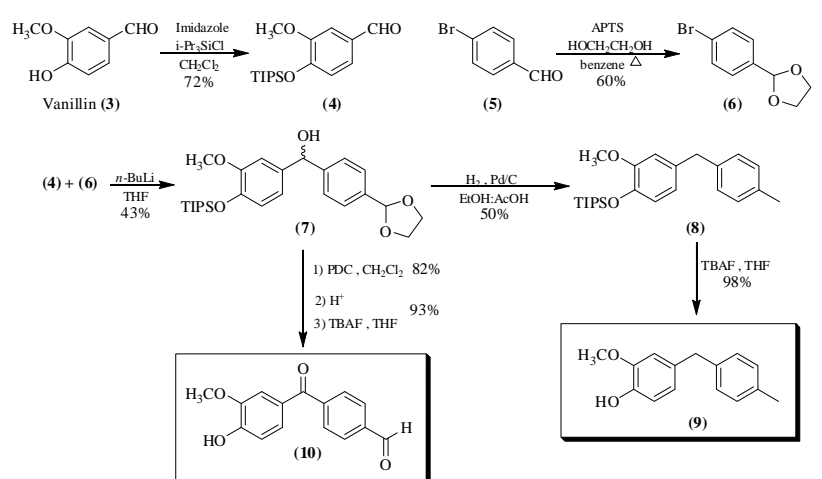

Scheme 1. Synthesis of the new ligands.

Moreover, compound 7 was submitted to an oxidation reaction with pyridinium dichromate (PDC) in dichloromethane and subsequent removal of the acetal and silicon groups, giving rise to ligand $\mathbf{1 0}$. The overall yields from compound 1 were $15 \%$ and $24 \%$, respectively for the ligands 9 and 10 .

\section{CONCLUSION}

Our research group is currently performing structural and functional studies of the synthetic compounds associated with specific proteins by crystallographic analysis. The success in the preparation of the ligands $\mathbf{9}$ and $\mathbf{1 0}$ enables to continue the development of new ligands with greater therapeutic value.

\section{ACKNOWLEDGEMENTS}

The authors thank FAPESP and CNPq for financial support.

\section{REFERENCES}

${ }^{1}$ Barra, G. B.; Polikarpov, I.; et. al. Arq. Bras. Endrocrinol. Metab. 2004, 48, 25

${ }^{2}$ Chiellini, G.; Nguyen, N-H.; Yoshihara, H. A. I.; Scanlan, T. S. Bioorg. Med. Chem. Lett. 2000, 10, 2607.

${ }^{3}$ Borngraeber, S.; Budny, M-J.; Chiellini, G.; Cunha-Lima, S. T.;

Togashi, M.; Webb, P. PNAS 2003, 100, 15358. 